Revista Destaques Acadêmicos, Lajeado, v. 9, n. 3, 2017. ISSN 2176-3070 DOI: http://dx.doi.org/10.22410/issn.2176-3070.v9i3a2017.1459 www.univates.br/revistas

\title{
O PSICÓLOGO E A UNIDADE DE TERAPIA INTENSIVA (UTI): UM OLHAR PELA FOTOGRAFIA
}

\author{
Claudimara do Prado ${ }^{1}$, Gisele Dhein ${ }^{2}$
}

Resumo: O trabalho do psicólogo no hospital é cada vez mais valorizado e essencial para o cuidado integral, tanto dos pacientes e familiares quanto dos trabalhadores. A psicologia em suas diversas áreas de cuidado tem ganhado espaço e sendo requisitada em várias áreas, entre elas a Unidade de Terapia Intensiva (UTI). Este artigo tem como objetivo refletir sobre a prática do profissional psicólogo em UTI. Trata-se do resultado de uma pesquisa qualitativa, onde, através da fotografia, três profissionais psicólogos relataram suas compreensões quanto às práticas psicológicas neste espaço. Como resultados podemos relacionar as imagens com suas vivências e práticas com a teoria.

Palavras-chave: Unidade de Terapia Intensiva (UTI). Psicólogo. Hospital. Fotografia.

\section{INTRODUÇÃO}

O presente artigo aborda o resultado de uma pesquisa, cujo objetivo foi refletir sobre a prática do profissional do psicólogo na UTI, através da fotografia. O trabalho do psicólogo no hospital está cada vez mais valorizado e compreende-se como essencial para o cuidado integral, tanto dos pacientes e familiares quanto dos trabalhadores. A psicologia em suas diversas áreas de cuidado tem ganhado espaço e sendo requisitada em várias áreas, entre eles a Unidade de Terapia Intensiva (UTI). Esta é a unidade onde pacientes graves e de alto risco são internados. Muitos deles, com grande chance de recuperação, mas também pacientes terminais, isto é, aquele que muitas vezes está sendo cuidado paliativamente.

O psicólogo carrega durante sua formação muita teoria e dedicação, o que deve continuar para poder trabalhar no hospital, combinado a aspectos teóricos, filosóficos, emocionais e de personalidade, que farão ele ter discernimento para saber os seus limites pessoais. $\mathrm{Na}$ atuação hospitalar, ele pode perceber uma enorme diferença entre teoria e prática, pois dentro de qualquer instituição de

1 Graduanda em Psicologia. Univates, Lajeado/RS. cprado@univeso.univates.br

2 Psicóloga e docente na Univates. Mestre em Psicologia (PUCRS). giseled@univates.br. 
saúde existem normas de funcionamento e termos técnicos, o que às vezes são muito distantes do que foi estudado na graduação. Portanto, esses profissionais se deparam com desafios e precisam se adaptar às normas da instituição, que agora também os atravessa (ANGERAMI-CAMON, 2010). Atualmente as universidades preparam cada vez mais os estudantes para atuarem na área hospitalar, porem há cerca de 10,15 anos atrás não eram tão preparados assim, por isso a diferença da teoria e pratica mencionado à cima.

O trabalho do psicólogo na UTI é fazer com que o paciente tenha um cuidado integral, com suas subjetividades e particularidades respeitadas dentro de suas demandas e possibilidades, além de apoiar e informar a família dos processos que o indivíduo enfermo está passando, ou seja passar a informação de uma maneira menos técnica. Buscar entender o sofrimento e a doença, orientar como será o tratamento e evolução do caso, auxiliar os colegas profissionais da saúde como fazer este cuidado de forma multidisciplinar, onde todos buscam juntos a melhor qualidade de vida ou de morte deste paciente, e assim realizar os encaminhamentos para as redes de cuidado conforme necessidade do paciente e família (PORTO; LUSTOSA, 2010).

A UTI é caracterizada por dispor de uma aparelhagem de cuidado altamente complexa, os profissionais que nela trabalham são técnicos especializados em cuidados específicos. Assim, é um espaço onde os pacientes críticos estão internados, gerando uma certa angústia e preocupação aos familiares, amigos e até para os profissionais da saúde que atuam neste espaço, pois a doença afeta biopsicossocialmente o sujeito que está ali internado (MACHADO, 2004).

A partir do aumento das tecnologias em exames, máquinas e evolução no conhecimento das medicações, a UTI tem cada vez mais condições de cuidado para o paciente em estado grave, pós-cirúrgico. Durante muitos anos, o acesso à UTI para famílias e amigos era restrito, até mesmo os profissionais da saúde; poucos circulavam dentro desse espaço, em função de cuidado com a contaminação e infecções.

Atualmente, com as políticas de humanização e aumento das tecnologias de prevenção a contaminações e infecções, os pacientes podem receber visitas em horários específicos, e muitas vezes com autorização prévia crianças realizam visitas aos seus parentes, pois faz parte do cuidado, tratamento deste paciente. Assim como o atendimento multidisciplinar que geralmente é composto por um médico intensivista, médico especialista, enfermeiro, técnico em enfermagem, fisioterapeuta, nutricionista, psicólogo, acompanhante terapêutico, assistente social, farmacêutico e fonoaudiólogo (CHEREGATTI et al., 2010).

Em relação ao trabalho humanizado e de maneira integral, a Política Nacional de Humanização da Atenção e Gestão do Sistema Único de Saúde (SUS) e Política Nacional de Humanização (PNH) vêm trabalhando com novos modos de produção de saúde e tem a intenção de gerar processos de trabalhos onde se relacionem a atenção, gestão, clínica, política, produção de saúde e 
subjetividade. A ideia é que todos profissionais participem desse movimento, superando desafios que a prática em saúde oferece, entre eles novos modelos de produção e circulação de poder. Os valores evidenciados nessa política são a autonomia e protagonismo dos sujeitos, onde estes são atuantes no seu processo de saúde, doença e tratamento. Isso ocorre através de informações e rede de cuidados que se constroem. Fortalecimento das redes de saúde, envolvendo trabalhadores, gestores e população são o desafio para novas práticas de cuidado e saúde (PASCHE, 2010).

Poder oferecer, assim, um trabalho diferenciado e de forma integral ao paciente, o que produziria mais saúde e cuidado a esse indivíduo, na promoção de saúde, conhecendo um pouco mais da vida desse paciente para entender sua doença e como se relaciona com ela. $O$ fortalecimento de vínculo gerado com a equipe de saúde processo de humanização facilita que o paciente seja atuante no seu Plano Terapêutico, que é quando o paciente e equipe de saúde juntos constroem um plano de terapia de acordo com suas demandas e possibilidades, e procedimentos necessários. Pois as ações de cuidado são feitas por ambas as partes, de quem cuida e de quem é cuidado, gerando autonomia para os usuários do serviço de saúde e melhor resultados para os trabalhadores da equipe (MERHY; FEUERWERKER, 2009).

\section{PROCEDIMENTOS METODOLÓGICOS}

A pesquisa através de fotografias são dispositivos que, segundo Justos e Vasconcelos (2009), permite olhar para as demandas a partir dos olhos do outro, observar a potencialidade das imagens e relacionar com a fala dos profissionais, onde trazem a subjetividade e particularidade de cada um e a maneira que enxerga seu trabalho, o que ele simboliza através da produção fotográfica de cada uma das psicólogas que se dispuseram a participar da pesquisa.

Assim, este artigo é resultado de uma pesquisa qualitativa, de cunho exploratório, cujo objetivo foi refletir sobre a prática do profissional da UTI, através da fotografia. A pesquisa foi realizada com três psicólogas que atuam em Unidades de Terapia Intensiva adulta, infantil e pediátrica no Vale do Taquari e Alto Uruguai/RS. As profissionais foram escolhidas de forma intencional e contatadas por e-mail, primeiramente, para explicação do projeto e convite. As entrevistadas possuem de 10 a 18 anos de formadas e idades entre 34 e 44 anos.

Com o aceite recebido, solicitamos que as profissionais produzissem uma foto, com seu celular, que representasse o seu trabalho na UTI. Solicitamos que não houvesse pessoas nas mesmas e que, preferencialmente, não fossem produzidas no espaço hospitalar para proteger o nome da instituição e as pessoas, trabalhadores, pacientes etc. O prazo para produção foi de sete dias, sendo que as imagens foram enviadas por e-mail, com a produção, também, de uma legenda para foto. 
A ideia de se trabalhar com a fotografia, imagem como uma opção de comunicação, faz com que a entrevista seja mais rica em detalhes, é o olhar subjetivo de cada uma das profissionais que participaram da pesquisa, de acordo com que elas representam e associam a cada imagem produzida e legendas apresentadas. Usar as imagens para se produzir uma olhar crítico sobre elas e o que elas representam para nós, fazermos refletir sobre o que se está vendo, o que as imagens passam para nós (SCHWERTNER; MUNHOZ, 2017).

Também foram realizadas entrevistas semiestruturadas com cada profissional em seu consultório particular, onde que foram gravadas e posteriormente transcritas. As questões norteadoras seguiram os objetivos da pesquisa, onde as vivências e percepções quanto às práticas psicológicas no espaço da UTI foram exploradas. As entrevistadas foram identificadas com a letra $\mathrm{P}$, seguidas de um número, para manter o sigilo da identidade das entrevistadas. Importante salientar que a pesquisa foi aprovada pelo Comitê de Ética da Univates, CAAE 62786516.4.0000.5310, e seguiu os preceitos éticos previstos na Resolução 466/2012.

A análise dos dados ocorreu através da cartografia, que se dispõe a promover a pesquisa com as realidades no contexto entre sujeito e objeto, lidando de forma flexível com os dados da pesquisa, focando na produção de realidade. Para cartografia, a objetividade e a subjetividade andam juntas, pois uma perpassa a outra no processo de análise, nas fronteiras do sujeito e objeto que estão diferentes a cada vez: "Ao fazê-lo, a cartografia lança luz sobre processos em que sujeito e objeto definem-se mutuamente, um em função do outro" (BARROS; BARROS, 2013, p. 374).

Para a cartografia, é importante todo processo de participação na construção do objeto, investigar como a objetividade se orienta ao que se propõe. Pois o processo de experiência entre sujeito e objeto é o que norteia o procedimento da pesquisa e análise objetiva e subjetiva. O que move essa análise de dados é o problema, a inquietude, problemas com os resultados que nos fazem ter mais problemas para serem pesquisados (BARROS; BARROS, 2013). 


\section{RESULTADOS E DISCUSSÃO}

\section{Dois corações ou mais: a importância do vínculo}

Figura 1- Afeto $^{3}$

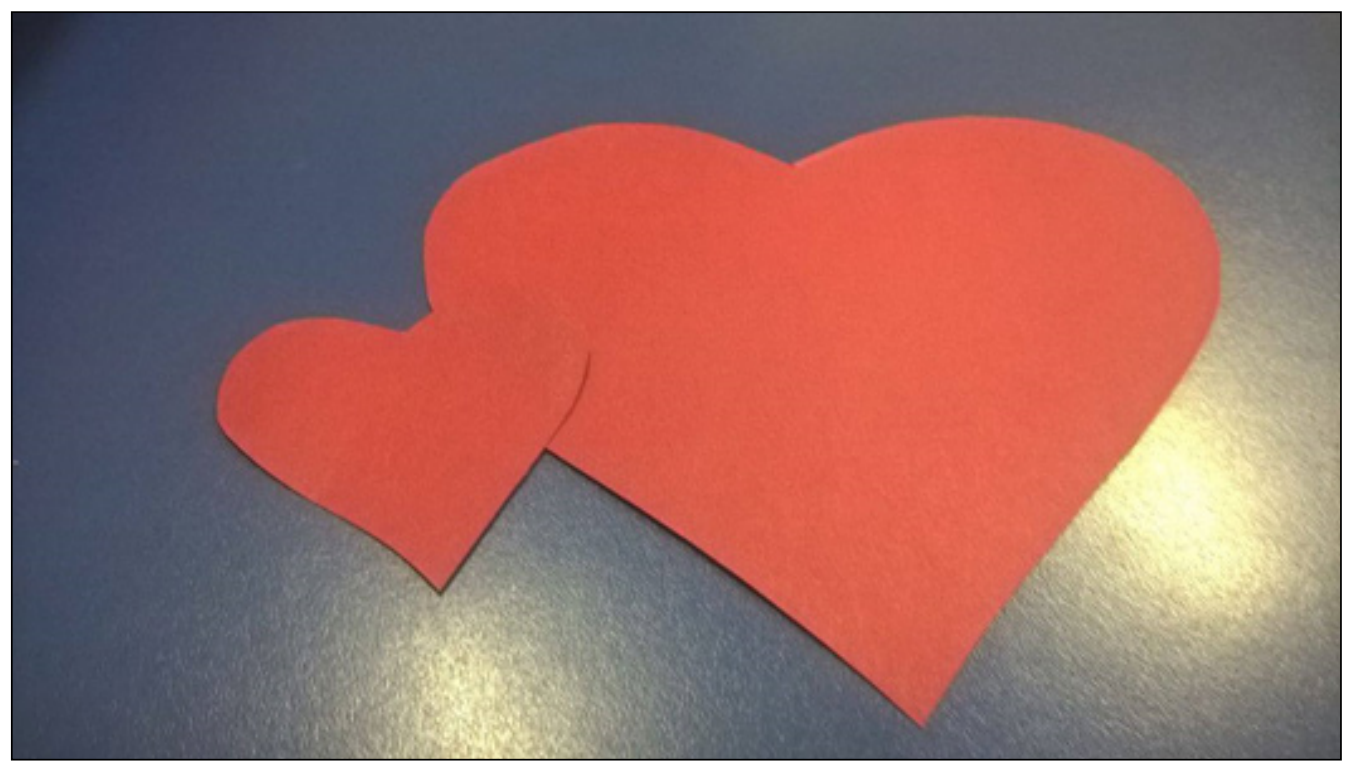

Fonte: P1

Nesta parte do trabalho trazemos a importância do vínculo entre família, paciente e profissionais da saúde para a melhora dos pacientes, e também preparação para o que acontecer. Pois quando a equipe é referência para a família, existe uma relação de vinculo, segurança para passar pelo período de internação, alta ou óbito.

Nas Unidades de Terapia Intensiva inicialmente o acesso era restrito em função do risco de contaminações. Na UTI Neonatal não era diferente, sendo ainda mais rígidas as regras de visita. Os bebês eram isolados apenas com acesso aos profissionais que atuam na UTI. Em função disso, muitas crianças eram abandonadas pelas mães ou tiradas delas após o nascimento, não sendo possível a visita, o que dificultava o estabelecimento de vínculos, dessa forma, muitos bebês eram salvos, porém ficavam órfãos (VALANSI; MORSCH, 2004). A Psicóloga 1 enfatiza a importância da relação:

3 O título das figuras apresentados no artigo são as legendas produzidas pelas entrevistadas. 
P1: Eu escolhi dois corações, pra falar do meu trabalho na UTI pediátrica [...] os corações como eu coloquei simbolizam afeto [...]. Penso que cada mãe que eu vou atender, cada pai, que na verdade eu não atendo os bebês, mas atendo os pais, e eu atendo com afeto. No sentido de me colocar no lugar, de tentar acolher, de proporcionar um conforto para aqueles pais, ajudar eles a se sentir melhor e isso vincula ao pequeno coração que é do bebê.

Atualmente, este processo já é bem diferente. Com a implementação da Política Nacional de Humanização, os bebês podem receber visitas em horários específicos, tanto dos pais quanto dos irmãos acima de 12 anos. $\mathrm{O}$ Ministério da Saúde (BRASIL,2014) implantou, na maioria das UTIs, o Projeto Canguru. Com autorização médica, as mães podem segurar seus bebês por algum tempo, iniciando o vínculo mãe-bebê, estimulando a amamentação, que é extremamente importante na recuperação e desenvolvimento do mesmo. As mães podem realizar a retirada do leite materno para alimentar seu bebê e os demais que necessitarem (VALANSI; MORSCH, 2004).

P2: [...] o médico me chama ou a própria família, eu faço atendimento então a praticamente todo os pacientes de UTI, e também os pais da UTI neonatal e dou suporte também para as famílias, principalmente na UTI geral, claro, na UTI neo principalmente por causa dos bebês. E uma coisa que eu faço é a liberação das visitas das crianças né, então a UTI adulto tu não pode entrar abaixo de 12 anos é proibido a visita no Hospital, então eu acabo liberando as crianças para entrar em algumas situações né, eu faço esse acompanhamento. E já UTI neonatal eu consegui fazer um projeto pra visita dos irmãos, que daí os irmãos entram visitar, então algumas situações enfim, a gente avalia bem algumas crianças assim com mais de 6 anos de idade, então a gente deixa entrar na UTI neonatal para visitar é uma visita rápida, esporádica, mas que beneficia muito o bebê, os pais, enfim, e os irmãos, é uma experiência muito bacana de ver a reação dos pequeninhos quando os irmãos vão visitar!

Existe também a dificuldade da mãe e do pai se vincularem com esse bebê, pois ele está em um ambiente estéril, com diversas pessoas - profissionais - podendo tocar nele e os pais ainda não. A mãe fica com um sentimento de insuficiência, pois cuidou durante toda a gestação desse bebê tão esperado e ele nasce doente, sendo que não pode fazer o cuidado dele. Na UTI neonatal, como o psicólogo não consegue realizar o trabalho com os bebês, ele faz um trabalho maior com a família. O papel do psicólogo é tornar-se referência para esses pais, já que nesse ambiente circulam vários profissionais e que provavelmente passarão um tempo significativo no cuidado de seus bebês. Entender as diferentes formas com que os pais lidam com esse processo, realizar grupos ou atendimentos individuais, o que não chega a ser uma psicoterapia, mas um acolhimento e suporte, são algumas das práticas possíveis neste espaço: 
"No acolhimento em espaços de saúde nas relações de trabalhador e paciente, existirá uma relação de dimensão individual que favorece esse acolhimento, a formação de vínculo" (BUENO; FRANCO; MERHY, 1999, p. 346).

Podemos pensar nessa criação e fortalecimento de vínculo através do toque e afeto, de colocar-se no lugar do outro e acolher o sofrimento, a angústia e a dor dos familiares e dos pacientes. Com uma atenção maior no toque das mãos, a fala, olhar, tudo isso pode beneficiar ainda mais as relações dentro do ambiente hospitalar que nos remete a um ambiente frio e impessoal. Por isso, é fundamental o vínculo construído diariamente entre profissionais da saúde, familiares e pacientes (MOURA; GUIMARÃES; LUZ, 2013, p. 2).

$\mathrm{O}$ trabalhador, independentemente de sua área, irá ter ações e intervenções de acordo com a demanda do usuário para produção de saúde do mesmo. Por isso, faz parte do trabalho do psicólogo orientar nesse momento tão delicado, oferecer cuidado e escuta diferenciados, onde se entenda a história do bebê e da família. Também auxiliar no vínculo mãe e bebê, proporcionando o entendimento da relação dos dois, orientando a comunicação entre família e bebê, fazendo com que acreditem e invistam na criança (VALANSI; MORSCH, 2004, p. 116).

P2: E a acho que poder abrir esse olhar da Psicologia realmente né, que às vezes não é só uma coisa psicológica que tem que olhar. A pessoa tem que olhar as necessidades que elas têm, enfim, eu acho que sim que é um trabalho bem diferente porque eu acho que quem está enfrentando uma situação de UTI, poder ter essa (pausa), um suporte de uma pessoa que está melhor que está podendo ser mais forte ali, podendo dar uma continuidade ali que, é totalmente diferente do que estar totalmente desamparado, às vezes a própria família não consegue amparar as pessoas que estão ali, de tão, de tão desestruturante que é uma situação de UTI. E acho que o psicólogo pode ter esse papel realmente de, de ajudar estruturar alinhavar essas coisas para também melhorar toda a questão da internação, enfim do quadro do paciente né.

Assim, a família torna-se um público de intervenção. Ela é a constituição social dos laços afetivos do paciente, sendo ou não consanguínea. Quando falamos de hospitalização, a família é o seguimento do paciente, pessoas fundamentalmente importantes para a recuperação do mesmo. Durante a internação em uma UTI, os familiares do paciente se desestruturam, ficam vulneráveis, por isso, a importância de se ter um olhar ampliado e realizar um cuidado, entender que a família desse paciente é uma extensão dele e interfere na sua recuperação. É esperado que após algum tempo a família se reestruture e divida as responsabilidades entre cada membro da família (FERREIRA; MENDES, 2013, p. 91). 
E como o sujeito é constituído como um todo, singular, dinâmico que interage dentro de uma sociedade, família, amigos é desorganizado organicamente e psicologicamente através da manifestação da doença. $\mathrm{O}$ que gera um abalo total em sua estrutura, a doença faz quebrar os vínculos do sujeito com ele mesmo e o mundo ao seu redor. A doença é vista como um inimigo a ser estudado e reconhecido, para assim poder combatê-la. O sujeito, durante esse processo, pode ir perdendo sua identidade e ressignificar de várias maneiras a doença, de acordo com suas crenças e subjetividade, que podem alterar ao longo do processo de internação (CHIATTONE et al., 2011).

É natural que durante esse processo os familiares não aceitem conversar com o psicólogo, ou equipe de cuidado, pois existe uma resistência inicial em admitir que precisa de um auxílio psicológico, pela dificuldade de aceitação de seu familiar estar em uma UTI, pois o mesmo pode fazer entrada a UTI de vários motivos sendo pós cirúrgico, acidente de trânsito, entre outras complicações e os familiares nunca estão preparados para lidar com essa situação.

P3: Isso é difícil né com o sofrimento muitas famílias não querem a aproximação do profissional por não ter um vínculo, por eu não conhecer, eu claro! Me apresento, chego de uma forma bem tranquila, me coloco à disposição... mas como eles estão muito preocupados, muito tensos, muito tristes com a situação do familiar adulto na UTI é difícil assim eu fazer atendimento, eu dou mais um suporte ali naquela hora da visita, por enquanto.

P1: Que na verdade eu não atendo os bebês, mas atendo os pais, e eu atendo com afeto. No sentido de me colocar no lugar, de tentar acolher, de proporcionar um conforto para aqueles pais ajudar eles a se sentir melhor.

P2: Muitas vezes eu converso com a enfermeira, às vezes quando os médicos estão também, e fico um pouco lá para ver a demanda, né, talvez não com o paciente, mas com o familiar. Então todo dia às 11:00 é o horário de visita na UTI e é o horário que eu consigo estar mais facilmente com os familiares.

Todas as psicólogas entrevistadas ressaltam a importância de se trabalhar com a família do paciente, até porque quando o paciente está inconsciente é impossível a comunicação. Com os pacientes intubados, por exemplo, a comunicação é de forma gestual. As entrevistadas ressaltam a importância do estudo e pesquisa para o entendimento das doenças e termos técnicos usados no hospital.

É necessário fazer um trabalho em conjunto de acolhimento, juntamente com a assistente social e acompanhante terapêutica, por exemplo, ou com 
outros profissionais que fazem parte das equipes para todos entender os termos usados e poder tirar dúvidas e fazer questionamentos sobre o trabalho realizado. O trabalho de cuidado em rede, que seria encaminhar, quando necessário, o paciente antes de sua alta ou familiares que necessitarem a um atendimento em saúde em outro local. Para se ter um cuidado continuado, após a internação hospitalar, as redes de cuidado devem ser estabelecidas (BRASIL, 2009).

\section{Uma equipe multiprofissional: o movimento da interdisciplinaridade}

Imagem 2: Metamorfose

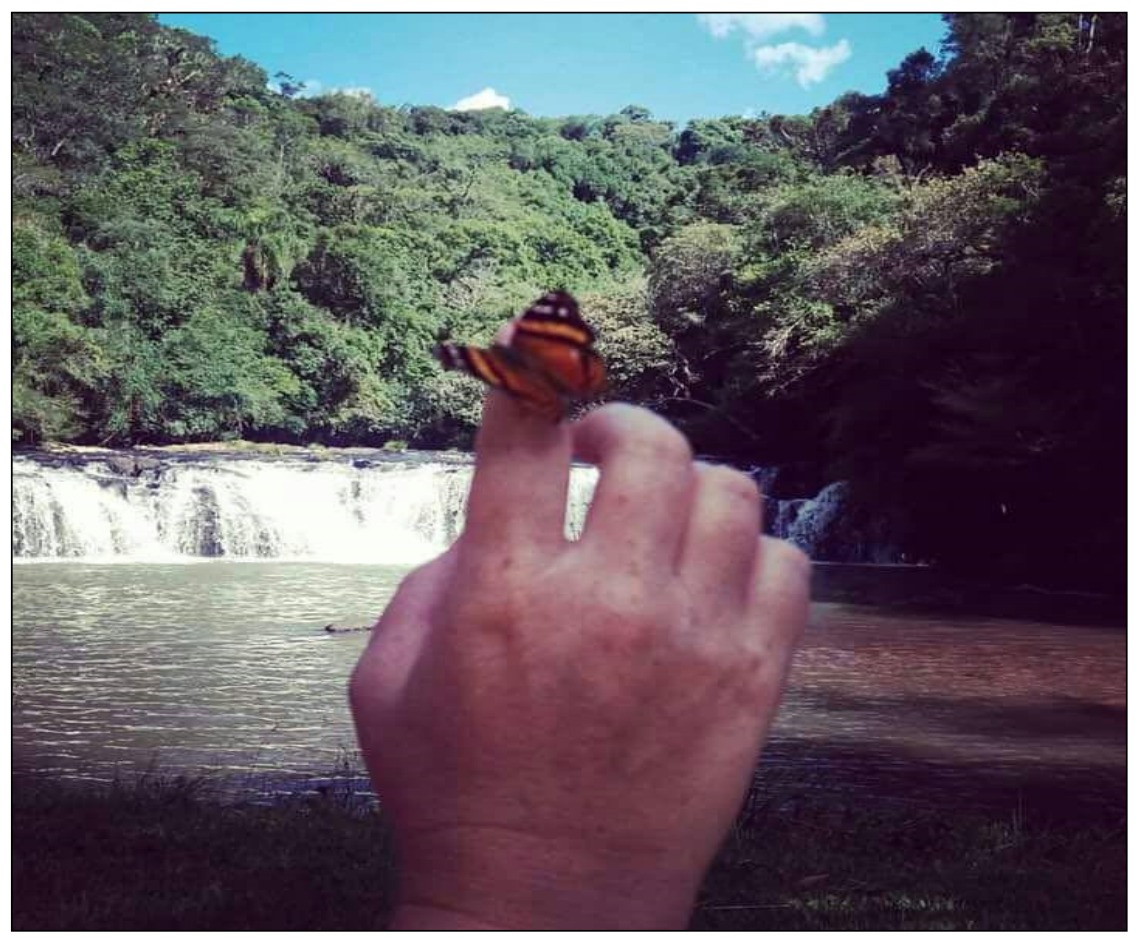

Fonte: P2

As UTIs são locais de trabalho instável, de uma hora para outra pode acontecer um óbito ou uma melhora repentina, é um lugar de movimentos e mudanças. Segundo a Psicóloga 2, é um espaço de metamorfoses, onde os pacientes e profissionais da saúde são perpassados pelos sentimentos e emoções que este lugar oferece no dia-a dia:

P2: Eu trabalho na UTI neonatal e na UTI adulto, eu gosto muito da borboleta por que eu acredito que é uma metamorfose em todos os sentidos né, muitas vezes a borboleta, o que ela representa né, 
ela é uma larva, vai se desenvolvendo se torna uma borboleta linda e ao mesmo tempo ela regride em alguns sentidos, eu acho que isso é o que acontece na UTI né, muitas, muitas metamorfoses, tanto para o bem quanto para o mal né. Muitas pessoas morrem, outras me surpreendem e melhoram muito rápido, a questão do desenvolvimento assim, os bebês... pensei muito nos bebês prematuros, como eles se desenvolvem, né, como eles nascem pequenininhos e se tornam lindas borboletas depois. E a questão da mão, por que eu acho que a gente sempre enquanto psicólogo dá essa ajuda e participa ativamente dessa transformação, né, não é só os cuidados médicos e enfermagem e sim o cuidado que a gente tem enquanto psicólogo, tanto com os bebês com os pais, tanto com os pacientes de UTI adultos, esse acompanhamento que a gente dá. E ao fundo eu acredito que as águas, né, representam muito assim, tem a cachoeira com a água mais agitada, enfim depois vem a calmaria ou vice e versa né, que as UTIs têm muito isso, ao mesmo tempo que está muito calma ela se torna agitada e ao contrário também né, da instabilidade que se tem dentro de uma UTI. E eu acho que nós, enquanto psicólogos, podemos ajudar e muito a tornar isso mais estável e a gente vê muitas transformações dentro, eu vejo muita transformação dentro da UTI. As pessoas dizem que a UTI é morta, é fim de vida, e eu já vejo o contrário, vejo muita morte e muita gente realmente sendo borboletas, né, saindo realmente do seu casulo e saindo realmente e melhorando e vivendo a vida. A gente vê realmente muitas coisas positivas dentro de uma UTI.

O trabalho de maneira interdisciplinar e em equipe multiprofissional apareceu nas falas das três psicólogas entrevistadas, pois como todas atuam nas UTIs adulta, pediátrica e neonatal, realizam um trabalho compartilhado com os demais profissionais da saúde, como enfermeiros, técnicos em enfermagem, nutricionistas, acompanhantes terapêuticos, assistentes sociais, fonoaudiólogas e médicos. A interdisciplinaridade permite um trabalho conjunto, com conversas entre si, trocando ideias e formas diferentes de ver o paciente, elaborando um acolhimento, proporcionando um atendimento muito mais completo e integral. Os problemas são resolvidos conjuntamente, permitindo que se construa o cuidado singular para cada paciente: "Ela tem a ver com a procura de um equilíbrio entre a análise fragmentada e a síntese simplificadora, assim como entre as visões marcadas pela lógica racional, instrumental e subjetiva" (LEIS, 2005, p. 2).

P2: A gente tem uma reunião de equipe na quarta-feira e a gente discute todos os casos. [...] Daí participa médicos, assistente social, fono, fisioterapeuta, a nutri, daí a gente vai trocando, tipo esse precisa fisio, esse precisa da fono, esse precisa atender os pais, esse precisa de uma questão mais de organização social daí entra, é bem legal assim. 
Diferente da multidisciplinaridade, onde os profissionais atendem um mesmo indivíduo, percebendo suas necessidades dentro da sua área e não conversam entre si, sendo o paciente atendido por vários profissionais da saúde, porém sem ligação nem troca entre eles, o que faz o atendimento ser individualizado. A seguir um exemplo de trabalho multidisciplinar:

P2: Então, meu trabalho na UTI é quando eu sou solicitada, avaliação, enfim, mas eu realizo visitas um dia sim um dia não né, então eu vou segunda quarta e sexta na UTI, que é uma coisa que o Ministério da Saúde exigiu de uma equipe multidisciplinar, então eu e a Assistente Social, a gente se reveza e a gente acompanha, acaba acompanhando todos os pacientes.

P3: [...] da uti neonatal a gente oferece grupos para os pais que estão com os bebês internados né então a gente tem uma reunião a cada um mês e meio a gente faz uma reunião com a equipe multi. Que daí sou eu, a terapeuta ocupacional, assistente social, enfermeira e a nutricionista. Né, porque são grupos com 5 módulos onde cada profissional vai abordar da sua especificidade, né!

No ambiente hospitalar existem diversos profissionais da saúde e entre eles máquinas e equipamentos para manutenção da saúde e cuidado de cada paciente. A relação dos profissionais com as máquinas, essa sincronização e equilíbrio, transposição de tecnologias durante a internação dos pacientes, gera uma melhora nos resultados do tratamento e aceitação dos usuários no serviço hospitalar.

Merhy e Feuerwerker (2009) identificam que entre o profissional da saúde e o paciente são utilizadas três "caixas de ferramentas tecnológicas", como saberes e materiais, que auxiliam no tratamento do paciente. A primeira é a que utiliza equipamentos físicos que permitem acessar o paciente, acontece o trabalho morto das máquinas e trabalho vivo de quem opera, conhecida como tecnologias duras. A segunda caixa é o olhar do profissional da saúde sobre o paciente, com objetivo de intervir de forma correta a partir de seu conhecimento, intituladas de tecnologias leve-duras. E a terceira e última caixa é a da relação entre profissional e o paciente, o cuidado, escuta, formação de vínculo, que permite conhecer e fazer com que o paciente seja atuante no seu processo de saúde e doença, podendo compreender e fazer escolhas; a partir disso, são chamadas de tecnologias leves.

Nas entrevistas com as psicólogas podemos perceber que a ferramenta mais utilizadas por elas são as tecnologias leves, é com elas que se aproximam do paciente e familiares, assim como dos colegas de trabalho, nesse processo de saúde e doença, vida e morte. As tecnologias vieram para dar suporte e melhorar o tratamento dos pacientes e sabendo combiná-las com o conhecimento e 
prática faz com que os resultados sejam ainda mais positivos dentro de uma instituição de saúde em que se tenha o saber, escuta, olhar e acolher.

Mas pela pesquisa, escuta da rotina das profissionais podemos constatar que o cuidado que elas realizam assim como procuram orientar os demais profissionais a realizar é o integral com o paciente. A integralidade unida ao processo de humanização seriam o início de um olhar diferenciado para então começar a pensar em uma intervenção, pois já se tem um conhecimento sobre o paciente, o que precisa ser trabalhado, suas questões, necessidades e demandas, assim como a importância do engajamento e colaboração dos profissionais que trabalham como promotores de saúde, para que esse cuidado aconteça. Como Merhy e Cecílio (2003) apontam, "o cuidado, de forma idealizada, recebido/vivido pelo paciente é somatório de um grande número de pequenos cuidados parciais que vão ser complementado" (p. 2). Com isso, percebemos a importância e responsabilidade que é colocada para os psicólogos de dar conta de atender e oferecer o melhor que pode para este usuário, de acordo com suas limitações e demandas. Poder, juntamente com os colegas, fazer um Plano Terapêutico e modificar conforme evolução desse indivíduo, com trocas de informações e vivências neste ambiente de trabalho.

P2: [...] sempre tem uma equipe que a gente troca, a gente dá suporte também assim para as minhas intervenções né, eu tenho uma boa relação com médicos, com técnicos com enfermeiros, então com a equipe mesmo com a nutri, com a fisio, é um trabalho bem bacana que a gente consegue desenvolver.

É muito importante o engajamento dos profissionais no cuidado dos pacientes e principalmente aos familiares na UTI, pois cada tratamento é diferente e a forma com que a família interage com a equipe faz com que exista vinculo, cuidado, confiança. Preparar as famílias para o tratamento necessário, processo de alta ou óbito. 


\section{Uma porta para a vida ou para a morte}

Imagem: 3: Porta de entrada

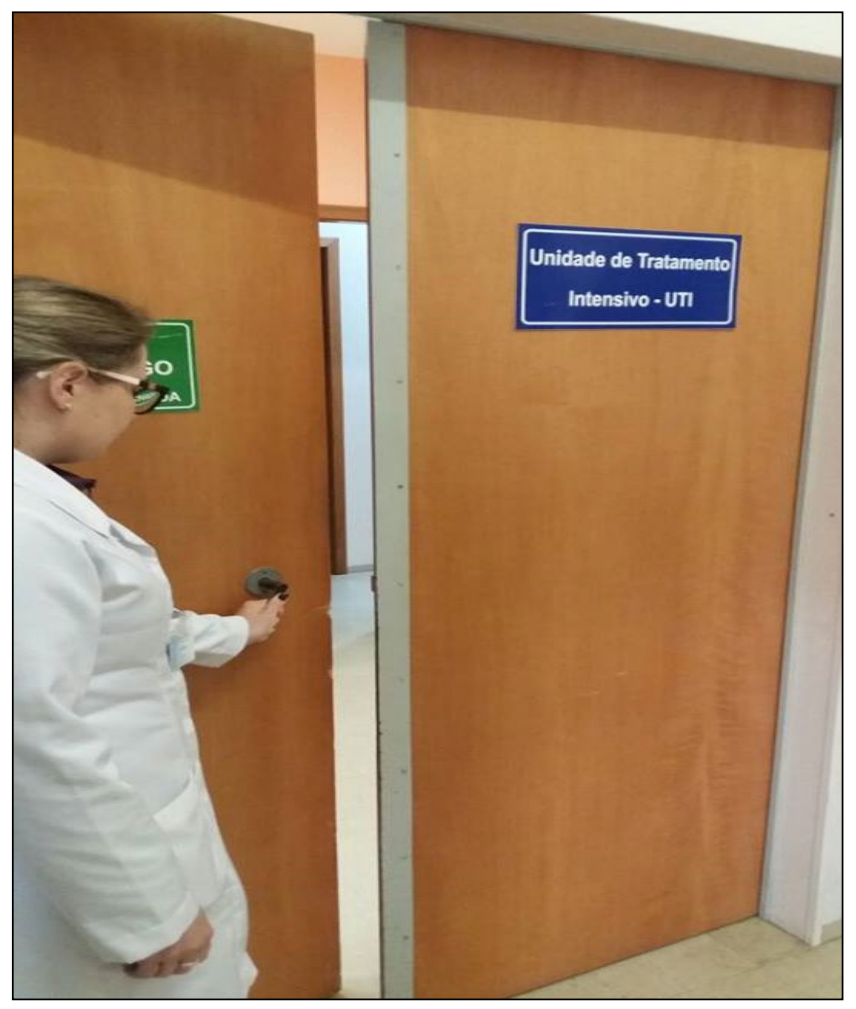

Fonte: P3

A UTI é uma porta de entrada tanto para a vida quanto para a morte. E durante as falas das entrevistadas, esse é uma das maiores dificuldades de se trabalhar no hospital, o entender e aceitar o fim de uma vida. No momento da morte, a equipe de saúde, de alguma maneira, é afetada; porém, essa passagem pode ter diversas interpretações de acordo com o significado que tem para cada um, e como é importante falar sobre ela, pois faz parte do ciclo de vida humana.

P2: As pessoas têm dificuldades de lidar com a morte de falar sobre isso e acho que hoje em dia eu encaro isso de uma forma bem diferente e a gente tem que falar sempre sobre isso.

Com o passar dos tempos e de acordo com cada cultura, a morte é encarada com rituais diferentes. Atualmente, a maioria dos óbitos ocorre no hospital, deixando de ser nas residências das famílias. Com isso, ela é acompanhada por diversos profissionais da saúde que lidam diariamente com a morte, fazendo muitas vezes ser algo mais natural e que faz pensar e 
refletir sobre suas vidas e na condição humana que se finda. Ao mesmo tempo, pode haver a sensação dos profissionais de que falharam, fracassaram, foram vencidos pela morte, sendo que seu trabalho é de mantê-los vivo, ajudando o paciente nesse processo de se ter uma morte sem dor e digna (SPINDOLA; MACEDO, 1994, p. 9).

P3: Eu acho que a UTI, né, tanto adulta quanto a neonatal, a entrada do psicólogo, assim... a minha entrada foi feita de uma forma bem tranquila né! Assim... principalmente na UTI neonatal, então, eu acho que a porta, aquela coisa da entrada, né, significa muito. [...]. Então a porta é aquilo da entrada e quanto o meu espaço ainda pode ser construído dentro da UTI adulta né, principalmente na UTI adulta.

O psicólogo pode auxiliar a equipe nesses processos de morte de pacientes, facilitando a reflexão e compreensão sobre o trabalho realizado, sentimentos e emoções vividas, nomeando o que sentem e pontuando o que era possível e o que não era de oferecer ao paciente, sem culpabilização do profissional. O psicólogo pode orientar através de conversa e grupos de profissionais e equipe como enfrentar de forma adequada a morte de acordo com a subjetividade de cada um, pois cada situação é diferente. Entender a importância da relação com os familiares durante a internação, para melhor acolher e cuidar no processo de morte, pois o cuidado mais efetivo nesse momento é com os familiares (MENDES; LUSTOSA; ANDRADE, 2009).

A relação entre profissionais da saúde, familiares e pacientes auxilia no processo de elaboração e compreensão da morte, pois quando ainda se tem algum tempo é possível orientar os familiares sobre como proceder com paciente e auxiliá-lo em uma morte sem abandono e solidão. Pois normalmente relacionamos a morte com a solidão, dor e sofrimento.

A perda de um bebê é bem mais difícil de ser enfrentada pela equipe de saúde do que a de um adulto, pois segundo a Psicóloga 3:

[...] é, UTI Neonatal tem um outro viés assim, porque a gente tá vendo crianças recém-nascidas, tu está falando de vida, né. Agora parece que quando tu está na UTI adulta tu tá no final da vida, assim, essa sensação que dá então.

É muito importante nesse momento oferecer apoio, acolhimento, cuidado, privacidade, respeito aos pais e familiares, pois podem então segurar o bebê e realizar a despedida com o tempo que cada família necessita. Ela é perpassada por sentimento de impotência, frustração, culpabilização, pois esse bebê foi cuidado durante toda a gestação e nasce doente, chegando ao óbito (ALMEIDA; MORAES; CUNHA, 2016). 
P3: [...] sou muito chamada também na UTI Neonatal quando acontecem mortes né, e nesse momento a mãe tem todo o acesso a esse bebê então que ela nunca conseguiu pegar ela tem essa possibilidade então de pegá-lo mas, quando ele já não tem mais vida. Isso é algo assim bem chocante e geralmente me chamam, é algo assim que fico pensando assim porquê dessa ... né, claro, a gente dá o suporte, o quanto a gente tem que fazer todo o vínculo antes com o paciente para tu também... e é com os pais, né, pra tu poder estar ali te colocando no lugar e podendo auxiliar nesse momento tão difícil, tão triste, por isso agora eu lembrei que foram situações bem difíceis para mim o quanto profissional, né, de estar acompanhando essa mãe para pegar o seu bebê já sem vida, né.

Após esse momento tão difícil para os profissionais e a família, quando é estabelecido um vínculo e cuidado, a família traz um retorno positivo para a equipe, o sentimento de gratidão e agradecimento, fazendo que os profissionais sintam-se como tivessem o dever cumprido. "O envolvimento emocional é inevitável, pois esses profissionais acompanham esse bebê diariamente em seu turno de trabalho, desde sua admissão na unidade até o momento de seu óbito ou alta" (ALMEIDA; MORAES; CUNHA, 2016, p. 126).

A morte faz parte do ciclo de vida e é importante a vermos de outra forma, como um processo de findar e dar sentido a toda uma história que teve um começo, meio e fim, podendo ressignificar, retomar laços e reescrever a sua história para que no final faça um sentido, sem sofrimento, dor e culpa e encontrar o sentido de nossa existência (ARANTES, 2013). Os profissionais que puderam acompanhar esse processo com "a força e o amor para ficar do lado de um paciente moribundo, com o silêncio que vai além das palavras, saberão que tal momento não é assustador nem doloroso, mas um cessar em paz do funcionamento do corpo" (KUBLER-ROSS, 2012, p.112).

Observar a morte como uma luz que se apaga gradualmente, trabalhar com o paciente terminal é poder ver toda sua singularidade e tomar consciência da finitude da humanidade onde cada um de nós escreve sua história.

P2: [...] as pessoas pensam só em UTI e ligam à morte e eu sempre digo não é, é muito mais vida do que morte.

\section{CONSIDERAÇÕES FINAIS}

Pensar no trabalho do psicólogo de UTI é um reinventar-se a cada dia diante das diversas situações inesperadas. Lidar com a vida e morte como aliadas, observar o nascer e o morrer de bebês e adultos realizando o cuidado dos familiares. Conforme os relatos das psicólogas entrevistadas, o trabalho mais efetivo em UTI é realizado com os familiares dos pacientes, que são a extensão dos mesmos. A relação, criação de vínculo com a equipe, família e 
pacientes, orientando nas relações durante o processo de internação são essenciais para a família e paciente passar pela internação de uma forma menos dolorosa.

A importância e atravessamentos de uma equipe multidisciplinar com o trabalho interdisciplinar para tratar do paciente de forma integral, realizando troca, escuta, cuidado, vínculo e acolhimento, utilizando as tecnologias duras, leve-duras e leves, onde cada profissional usa suas ferramentas e realizam um trabalho conjunto, um perpassa o outro gerando um resultado positivo no tratamento e tempo de internação do paciente e situação da família.

E para finalizar o processo de morte que nas UTIs é o que mais ocorre e os profissionais precisam estar preparados e saber lidar com essa situação que afeta todos os profissionais, fazendo refletirem sobre suas práticas e vínculo criado durante a passagem no hospital. Ressignificar a morte de acordo com cada paciente e situação vivida.

As entrevistas fizeram com que pudéssemos conhecer as reais práticas dos psicólogos de UTI neonatal e adulta, dificuldades e facilidades, trabalho interdisciplinar, multidisciplinar, o trabalho efetivo com os familiares dos pacientes, os encaminhamentos para a rede de saúde e o lidar com a morte. Podermos fazer eles pensarem sobre suas práticas e podermos falar mais do trabalho do psicólogo de UTI que é pouco conhecido ou mesmo desconhecido na sociedade, porém tem ganhado mais espaço nos hospitais sendo essenciais para um cuidado integral dos pacientes e familiares. A fotografia como representação de seu trabalho e sentido que faz na vida de cada uma das profissionais, usar a imagem como uma forma a mais de comunicação e o que ela pode transmitir para cada pessoa que a observa e tem um olhar um sentido diferente, dando mais possibilidades de significar o que se vê faz com que esta pesquisa seja relevante para conhecer o trabalho do psicólogo hospitalar.

\section{REFERÊNCIAS}

ALMEIDA, F.A.; MORAES, M.S.; CUNHA, L.R. Cuidando do neonato que está morrendo e sua família: vivências do enfermeiro de terapia intensiva neonatal. Rev Esc Enferm USP , 2016; 50(n.esp):122-129.

ANGERAMI-CAMON, V. A. O Doente a Psicologia e o Hospital. Editora Cengage, SP. São Paulo 2010.

ARANTES, A. C.Q. A morte é um dia que vale a pena viver. 30 de abr de 2013 https://www.youtube.com/watch?v=ep354ZXKBEs

BARROS, L. M. R.; BARROS, M. E. O problema da análise em pesquisa cartográfica.

Rev. Psicol. v. 25, n. 2, pp. 373-390, maio/ago, 2013. 
BUENO, W. S.; FRANCO, T. B.; MERHY, E. E. - O acolhimento e os processos de trabalho em Saúde no caso de Betim, Minas Gerais, Brasil. Cad. Saúde Pública, Rio de Janeiro, 15 de abril-junho 1999

CECÍLIO, L. C. O.; MERHY, E. E. A integralidade do cuidado como eixo de Gestão Hospitalar. Campinas, Março de 2003.

CHEREGATTI, A. L.; BARRETO, A. P. M., GONÇALVES, C. C. S.; OLIVEIRA, E. A. M. Técnicas de UTI. São Paulo: Editora Rideel, 2010.

CHIATTONE, H. B. C.; SEBASTIANI, R. W.; FONGARO, M. L. H.; SANTOS, C. T. E a PSICOLOGIA entrou no HOSPITAL. São Paulo: Cengage Lerning, 2011.

FERREIRA, P.D.; MENDES, T.M. Família em UTI: Importância do Suporte

Psicológico Diante da Iminência de Morte. Hospital Regional de Santa Maria, Distrito Federal. Rev.SBPH vol.16 no.1, Rio de Janeiro- Jan/Jun- 2013.

JUSTO, J.S.; VASCONCELOS, M.S. Pensando a fotografia na pesquisa qualitativa em psicologia. Estud. pesqui. psicol. v.9 n.3 Rio de Janeiro dez. 2009

KUBLER-ROSS, E. Sobre a Morte e o Morrer. São Paulo: Martins Fontes. (2005)

LEIS, H. R. Sobre o Conceito de Interdisciplinaridade- Cadernos de Pesquisa Interdisciplinar em ciências humanas. ISSN 1678-7730 No 73-FPOLIS, Agosto 2005.

MACHADO, E.G.A. Enfermagem em Unidade de Terapia Intensiva. Editora Cultura e Qualidade, edição 2004.

MENDES, J. A; LUSTOSA, M. A.; ANDRADE, M. C. Impaciente Terminal, Família e Equipe de Saúde. Rev. SBPH v. 12 n. 1 Rio de Janeiro jun. 2009.

MERHY, E.E.; FEUERWERKER, L.C.M. Novo olhar sobre as tecnologias de saúde: uma necessidade contemporânea. In: MANDARINO, A.C.S.; GOMBERG, E. (Orgs.). Leituras de novas tecnologias e saúde. São Cristóvão: Editora UFS, 2009. p. 29-74.

MINISTÉRIO DA SAÚDE, Brasil (2014). Acesso em junho de 2017. http:/ / portalsaude.saude.gov.br/index.php/o-ministerio/principal/secretarias/562sas-raiz/dapes/saude-da-crianca-e-aleitamento-materno/14-saude-da-crianca-ealeitamento-materno/10387-vacinacao-infantil

MOURA, M. M. D.; GUIMARÃES, M. B. L.; LUZ, M. Tocar: atenção ao vínculo no ambiente hospitalar. Interface (Botucatu), v.17, n.45, p.393-404, abr./jun. 2013.

PASCHE, D. F. Humaniza SUS na Atenção Básica. Ministério da Saúde, Brasília 2010.

POLÍTICA NACIONAL DE HUMANIZAÇÃO, BRASIL (2003). Acesso em junho de 2017. http:/ / portalsaude.saude.gov.br/index.php/o-ministerio/principal/ secretarias/sas/humanizasus 
PORTO, G.; LUSTOSA, M. A. Psicologia Hospitalar e Cuidados Paliativos. Revista Sociedade Brasileira de Psicologia Hospitalar (SBPH), v. 13, n. 1, Rio de Janeiro, Jun. 2010.

SCHWERTNER, S.F.; MUNHOZ, A.V. Imagens da Escola e suas Funções na Contemporaneidade: $\mathrm{O}$ Discurso de Estudantes Concluintes do Ensino Médio. Imagens e Educação, v.7, n.1, p.58-69, 2017.

SPINDOLA, T. MACEDO; M.C.S. A Morte no Hospital seu Significado para os Profissionais. R. Bras, Brasília. v.47, n.2, p.1 08-1 1 7, abr./jun. 1994.

VALANSI, L.; MORSCH, D.S. O psicólogo como facilitador da interação familiar no ambiente de cuidados intensivos neonatais. Psicol. cienc. prof. v.24 n.2 Brasília jun. 2004. 